\title{
The International Children's Digital Library: Viewing Digital Books Online
}

\author{
Juan Pablo Hourcade, Benjamin B. Bederson, Allison Druin, Anne Rose, Allison Farber, \\ Yoshifumi Takayama \\ Human-Computer Interaction Laboratory \\ A.V. Williams Building \\ University of Maryland \\ College Park, MD 20742 USA \\ +13014057445 \\ jpablo@cs.umd.edu
}

\begin{abstract}
Reading books plays an important role in children's cognitive and social development. However, many children do not have access to diverse collections of books due to the limited resources of their community libraries. We have begun to address this issue by creating a large-scale digital archive of children's books, the International Children's Digital Library (ICDL). In this paper we discuss our initial efforts in building the ICDL, concentrating on an informal evaluation of innovative digital book readers.
\end{abstract}

\section{Keywords}

Children, digital libraries, books, book readers, graphical user interfaces.

\section{INTRODUCTION}

The importance of children's books in young people's lives cannot be minimized. Books can help children to understand who they are, explore the world around them, and contribute to a child's ability to be literate in today's society [11] [21] [26] [31] [33]. Access to diverse multicultural literature can be limited despite the best efforts of librarians, teachers, and parents. The financial resources for collections, particularly in urban areas are limited and insufficient to provide diverse collections reflective of today's school populations. We are working on bridging this gap by developing a large-scale digital archive of children's books called the International Children's Digital Library (ICDL). In this paper, we discuss our initial efforts in designing user interfaces appropriate for young children (ages 5-11) to access such an archive. In the sections that follow we discuss the need for research, our previous work, the goals of the project, our design methodology, and the results of our initial efforts, including an informal evaluation of the innovative book readers we introduce here.

\section{NEED FOR RESEARCH}

When children's books play an important role in young people's lives, research has shown an increase in children's cognitive, social, and motivational development [9] [20] [26] [31] [46]. In addition, access to narratives from different cultures can offer children opportunities to better understand the world around them as well as who they are in relation to that world [5] [7] [21]. Unfortunately, getting access to books for children from the United States and abroad can still be a challenge. Children in many communities have limited access to a wide variety of multicultural literature. Poor physical library and school facilities and limitations on funding for materials can lead to frustrated children, parents, and educators. However, with computer technologies becoming more widely available in school/public libraries and community centers, tens of thousands of books can be made available through online digital collections.

Developing new technologies appropriate for children can be challenging, since young people can have difficulty reading, typing, spelling, and are continually changing in their interests and abilities [15] [35] [41] [45]. Novel work in the HCI community has produced numerous approaches to visualizing searches and their results that may offer new opportunities for children [2] [22] [23] [30]. However, there are definite limitations to these systems when children are the users. Many interfaces are cognitively challenging due to abstract representations of Boolean search methods and the need to read result lists or query labels [15]. While there is an emerging and significant research field devoted to digital libraries and information retrieval, we have found that the vast majority of content and interfaces are targeted for adults or older students. For example, at last year's JCDL'01 conference, there were 76 papers, of which only two were focused on children's interfaces/content [15] [42].

Of the online digital libraries appropriate for children, there is a disappointing number of large-scale collections to explore. In January of 2002, the largest online digital collection of children's books we were able to find included only 67 titles. Out of 24 sites we found, a majority of these 
digital collections showed only titles, sometimes with summaries, reviews or associated activities [6] [10] [38] [43]. Others offered only options to purchase books [18] [29] [44]. Still other collections depended on out-ofcopyright materials [17] [19]. The site that currently includes the most digitized books online is "Children's Books Online for Free" [19]. This collection, as of January 2002 , includes 67 fully digitized books online, with plans to increase the number to 1,200 out of copyright titles. In evaluating the user interfaces of these sites for accessibility, it is clear that most were not designed primarily for use by children, but rather for access by adult researchers, teachers, or parents.

There is also a need for research in developing interfaces for children to read books on computer screens. Many researchers have looked at the difficulty of reading on a computer screen. O'Hara and Sellen compared reading from paper to reading on a computer screen [36]. These comparisons dealt mostly with document reading and marking by adults. Dillon has also done comparisons between electronic documents and paper and has proposed ways of evaluating interfaces for electronic documents [12] [13]. Shneiderman provides a nice summary of the research in this area [40].

Most of the research on book readers has come from industry. However, little has been published. Graham created the Reader Helper, a document reader meant to make it easy for adults to find relevant information in documents [25]. The Reader Helper highlights relevant information in a document and shows annotated thumbnails of the document's pages on the left side of the screen. Ginsburg el al. developed a reader for PostScript documents that shows thumbnails on the left side of the screen [24].

Today's industry standard book readers come from Microsoft and Adobe. Their e-book readers for personal computers are Microsoft Reader [34] and Adobe Acrobat eBook Reader [1], shown in Figure 1. Both Microsoft and Adobe suggest that the main advantage of using their products is their text-related features. Both products offer solutions for more screen-readable text (e.g. ClearType, CoolType). Both products also contain features for searching and annotating books, looking for words in the dictionary, and reading words out loud. Both products were mainly designed for adults reading long books or documents consisting mostly of text. Neither product provides major alternatives to their default screen layouts or visualizations of the books.

With these text readers, navigation between pages is primarily accomplished by using keyboard shortcuts or small next and previous page buttons, which are too small for young children. In Microsoft Reader 2.0, the riffle control, a widget that shows up when right-clicking at the bottom of a page can also be used to change pages. It allows the user to move to the next and previous pages, the next and previous section, and shows a bar that tells users their position in the book and allows them to jump to other parts of the book. The table of contents can be accessed through popup menus. Due to the fact that the riffle control is accessible by right-clicking, accessibility for children is limited. From our experience, many young children cannot distinguish between the left and right mouse buttons.

Adobe Acrobat eBook Reader 2.2 has similar navigation options, with small buttons to move to the next and the previous page, and a widget at the bottom of the screen that has similar capabilities to Microsoft's riffle control. The table of contents is also available through menus. While the right mouse button has the same functionality as the left mouse button in most cases, there is no full-screen option, so children can accidentally click on the operating system taskbar (on Windows).

Commercially available e-books for children generally use one of these two readers, although other options exist. For example, Antelope Publishing [3] offers its books in HTML format for children to read in a web browser.
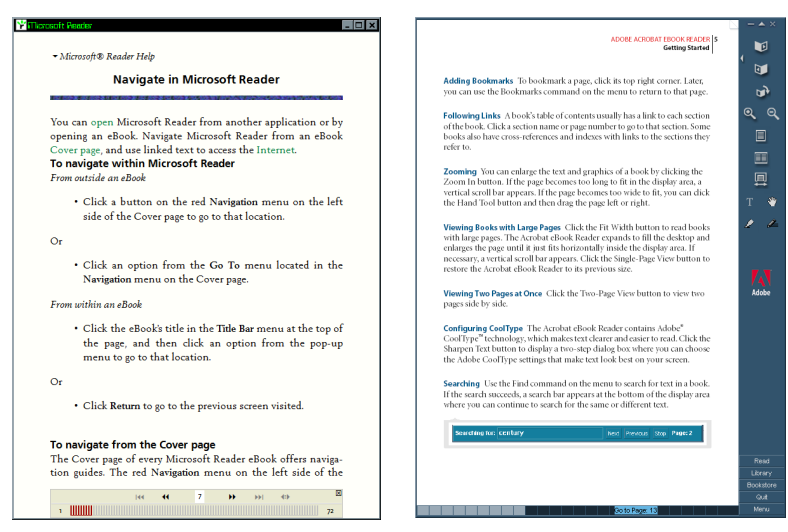

Figure 1: On the left, Microsoft Reader 2.0 with the riffle control open at the bottom of the window. On the right, Adobe Acrobat eBook Reader 2.2, showing its navigation bar at the bottom of the window.

\section{OUR PREVIOUS WORK}

For the past three years, we have been developing SearchKids, a graphical direct manipulation collaborative interface for searching, browsing, and viewing query results of digital libraries. Our initial prototype is devoted to multimedia information on animals [15] [28] [39]. However, the technologies we developed are not limited to this content area and we are currently extending it to support books.

SearchKids consists of three areas, shown in Figure 2, through which users can look for media about animals. The zoo area provides a way of browsing the contents of our animal digital library in a familiar setting. When entering the zoo area, users see the map of a virtual zoo. By zooming into parts of the zoo, children can find representations of animals and through them, access media. 

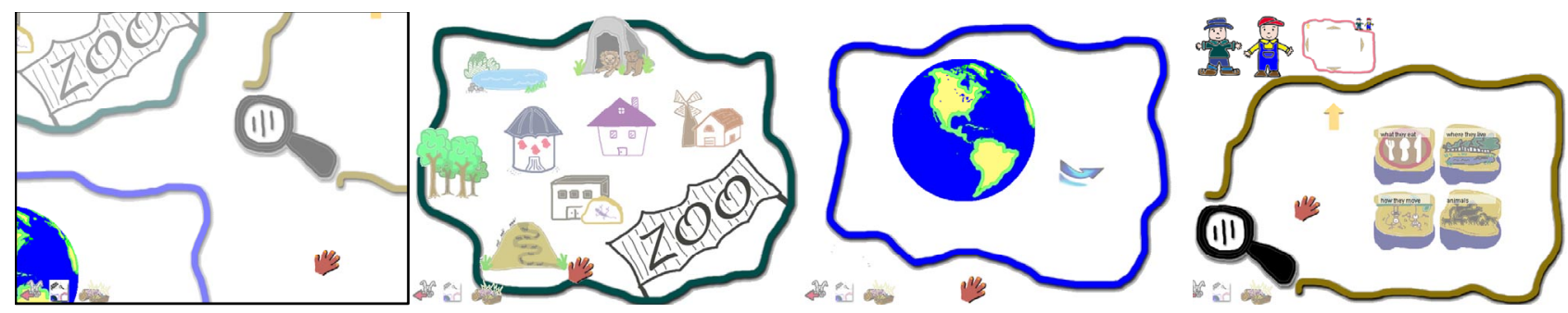

Figure 2: From left to right: SearchKids' initial screen, the zoo area, the world area, and the search area.

The world area provides a way of browsing our animal digital library by looking for animals geographically. It presents children with a globe they can spin and zoom into. By zooming into a region of the world they can find representations of the animals that live in that part of the world and through them, access media.

The search area gives users the ability to visually specify and manipulate queries. It also provides previews of and access to query results. Children can form queries by selecting icons that represent query terms and are organized hierarchically. The icons at the top of these hierarchies represent the different categories available for searching. Selecting icons from different categories returns an intersection of the items represented by the icons. Selecting icons from the same category returns a union of the items represented by the icons. We conducted a study of the effectiveness with which children could pose queries using the search area and obtained encouraging results [39].

SearchKids supports simultaneous multiple users through multiple mice by using MID [27]. Our team has experimented with two modes of collaboration. In one mode, independent collaboration, a user's click on an interactive item is enough to interact with that item. In another mode, confirmation collaboration, all users must click on an interactive item in order to interact with it. We are currently analyzing data from a study we conducted on how these collaboration modes affect collaboration between children.

\section{PROJECT GOALS}

Our book digital library research has five primary goals. The first is to develop interface technologies that support children in using large amounts of digital information (e.g., searching, browsing, reading, and sharing). This paper describes our initial efforts in pursuing this goal.

The remaining goals include:

- To give children around the world access to international children's literature.

- To evaluate the impact such a digital collection can have on collection development and program practices of librarians who work with children.

- To evaluate the impact such a digital collection can have on children.
- To better understand data acquisition and rights management by using the development of this largescale digital library as a case study.

\section{DESIGN METHODOLOGY}

We believe that children should play an active role in the development of technology for children. Therefore, we have established an interdisciplinary, intergenerational team of researchers that include computer scientists, educational researchers, visual artists, library scientists, children and classroom teachers. To work together, we have used a combination of techniques known as Cooperative Inquiry [14] [16]. These techniques offer an approach to research that can be used to gather data, develop prototypes, and forge new research directions.

The group of children we work with consists of three boys and four girls aged 7 to 10 years old. They work as design partners with adult researchers in our lab on this and other projects. During the school year, they come to our lab twice a week, each visit for one and a half hours. In order for everyone to get ready for the school year activities, we run a two-week intensive design program every summer. During these two weeks, the children spend 8-hour days at our lab working with adult researchers on various design problems.

\section{SUMMER SESSION}

During the 2001 summer session we began modifying our existing SearchKids digital library interface to support books. We began the session with everyone bringing in their favorite children's books. These books varied widely, from short books with mainly pictures and very few words, to chapter books with a few hundred pages of words. Some of the books were in languages other than English.

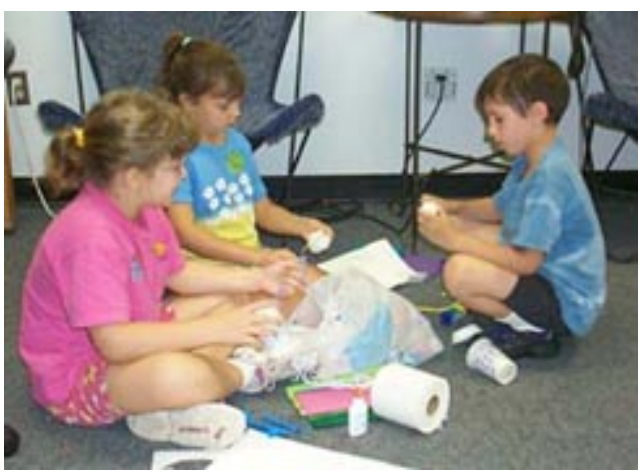

Figure 3: Children working at our lab. 
We first reviewed SearchKids with the children, and then brainstormed how to adapt it to books. From this, we decided to concentrate on three areas: how to adapt the existing searching and browsing capabilities of SearchKids to the domain of children's books, how to create an online community of book readers (like book clubs at a neighborhood library), and how to support the reading of books on a computer. We found it necessary that books be read on computer screens, as it would be difficult for public libraries with little resources to own specialized book readers, or be able to print the books. We therefore broke up into three groups to address each of those areas, each with children and adults.

The browsing and searching group extended the world area from SearchKids (Figure 2) for the ICDL, where it could be used to find books based on where they are from, what part of the world they are about, and where they are popular. Our current design has one globe that when zoomed into a geographical area reveals three options representing books from that area, about that area, and popular in that area. Zooming into one of these shows the appropriate books.

The browsing and searching group also found that the search area in SearchKids could be adapted for the ICDL. The main issue with using the search area was to determine the different categories by which books could be searched for. While the group came up with metadata many adults would come up with, such as subject and popularity, it also decided books should be searched by the feelings they evoke, and the color and shape of their cover. The group then looked at how books should be categorized by subject. After doing some research, the group concluded that existing cataloguing methods used at libraries such as the Dewey Decimal Classification and the Library of Congress Classification are not easy to follow by children. After looking for alternatives, the group settled on the classifications used by amazon.com, which children found much easier to follow.

The online communities group looked at how to provide a community experience. The group focused on book clubs to connect children reading the same books. They would provide information about books, and enable children to read them, rate them, select the feelings the books evoke, and write reviews. Children would also be able to read other children's reviews, and see their ratings and feelings selections. In addition, book clubs would provide quizzes, games, discussion areas, links to websites, and activities related to each book. Figure 4 shows a design mockup of a book club.

The group dealing with how to read books on the computer screen felt that in addition to traditional book reader features, children needed extra support for navigation. Partly due to the visual nature of many children's books, and partly due to the children's desire to flip through pages in a manner more similar to paper books, we designed two alternate readers. These readers were designed assuming the

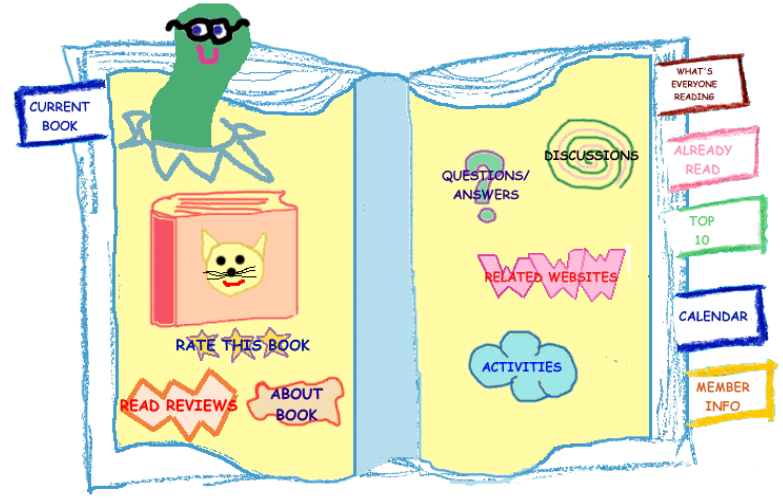

Figure 4: Book club design.

books were very visual, and had no more than approximately 50 pages. Our expectation was not that any one reader would be best in all circumstances, but that for some children, some books, and some tasks, different readers would be preferable.

In the comic strip reader (Figure 6), pages are laid out as if they were in a comic strip. The page of interest can be zoomed into to read it. The spiral reader (Figure 6) shows the current page in the middle of the screen, where the earlier pages get smaller in a spiral shape to the left and the following pages get smaller in a spiral shape to the right. Both readers are described in more detail below.

Following the reports by each group, we proceeded to adapt SearchKids to the needs specified by the searching and browsing group. By the end of our summer session, we managed to have a working prototype with a search area in which children could look for books based on subject, ratings, color and shape of the book cover, and feelings (see Figure 5). The search results showed the covers of the books that matched the search criteria. We also implemented a spinning globe through which books could be accessed based on where they were from. The children in our team created the art for the icons in the search area.

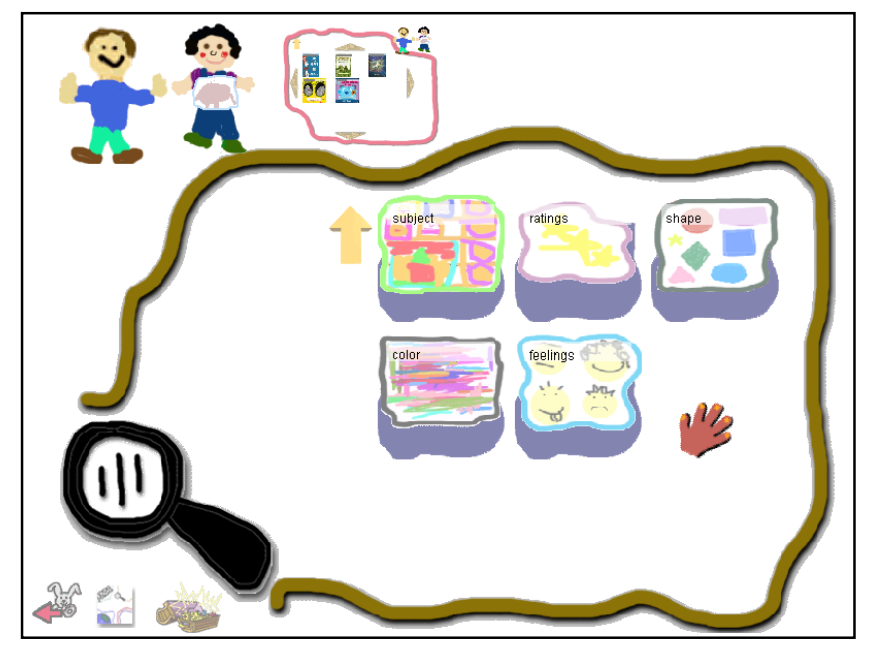

Figure 5: Screenshot of SearchKids search area adapted to book searching. 
At the end of the session, the children demonstrated the prototype to their parents.

\section{INFORMAL EVALUATION OF BOOK READERS}

We have continued our work on the ICDL, concentrating on book readers. We implemented the comic strip and spiral readers using Jazz [4], a graphics toolkit, and performed a pilot study to understand if these types of readers are effective for children. While we thought that different users would prefer different readers under different circumstances, we needed to validate this. We therefore set out to build prototypes of these readers in order to informally evaluate them with children. We thought the best way to test them would be to compare them with a more traditional reader.

\section{Description of Book Readers Standard Reader}

We built a reader with traditional interface mechanisms, which we will refer to as the standard reader. With this reader, a user can see one page at a time (Figure 6). The controls to read the book are at the bottom of the screen. The large left arrow takes the user to the previous page, while the large right arrow takes the user to the next page. Users can access the same functionality by using the left and right arrows and the "page up" and "page down" keys on the keyboard. No animation occurs when changing pages. We built this as the baseline because it provides the same basic functionality as the commercial readers.

\section{Comic Strip Reader}

The comic strip reader lays out book pages as if they were part of a comic strip (Figure 6). When the reader is started, the user sees all the pages in the book. The controls to read the book are at the bottom of the screen and are identical to those in the standard reader, with the exception of a "zoom out" button (not needed in the standard reader). The left and right arrows and the "page up" and "page down" keys have the same functionality as the arrows on the screen.

The user can also interact with the book by clicking on pages. When seeing the entire comic strip, clicking on a page smoothly zooms the user into that page. If the user is already zoomed into a page, clicking on that page zooms the user out, also accomplishable by clicking on the "zoom out" button. All zooming is animated over half a second. When zoomed into a page, the left and right arrows take the user to the previous and next page respectively. The transition between pages animates the view of the comic strip to the left or to the right as appropriate. If the end of a strip is reached, the view zooms out and then zooms in to the destination page.

Clicking on the left or right arrows when seeing the entire comic strip zooms the user to the previous or next page with respect to the last page the user visited. If the user clicks on the right arrow before visiting any pages (i.e. when starting the reader), then the view is zoomed into the first page of the book.

All pages in the comic strip reader have a border around them intended to give feedback to the user. Unvisited pages have a thick blue border, and pages that have been visited have a thinner magenta border (using standard web visitation colors). If the user's mouse cursor is over a page, the page's border changes to a thick red.

\section{Spiral Reader}

The spiral reader is the most novel of the readers we built. It shows the current page in the middle of the screen between two spirals (Figure 6). The spiral to the left shows the pages that come before the current page, while the spiral to the right shows the pages that come after the current page.

The spiral reader has the same screen and keyboard controls as the comic strip reader. Using the arrows changes the current page to the next or previous page and animates all pages accordingly around the spirals. Clicking on a page other than the current page makes that page the current page, animating all pages around the spirals in order to bring the new current page to the center of the screen. Clicking on the current page magnifies it so it occupies most of the screen in order to read its text more easily. Clicking on the current page again (or clicking on the "zoom out" button) takes the current page back to its
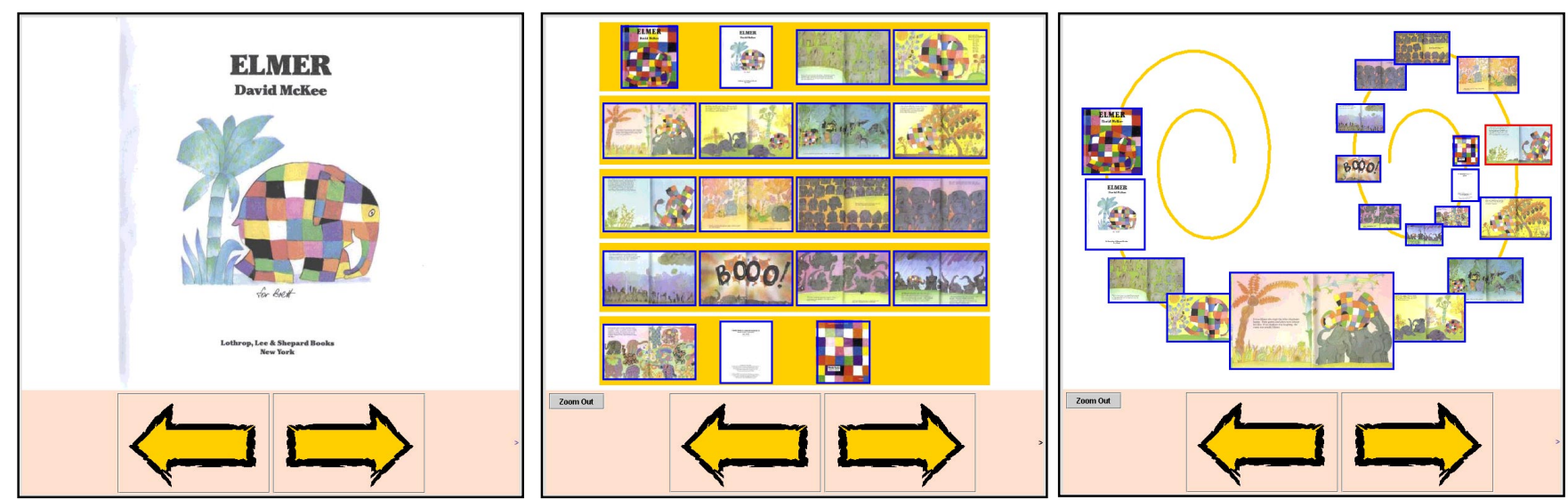

Figure 6: From left to right, standard reader, comic strip reader, and spiral reader. All readers are showing David McKee's Elmer [32]. 
normal size. Changes in size and zooming transitions are animated over half a second. When the current page is magnified, the arrows are still operational, animating the transition to the next and previous pages. However, we disabled the ability to click on another page to make it the current page, as very few other pages are visible, and clicks intended for the current page could end up on another page by accident.

The spiral reader uses colored borders around book pages in the same way as the comic strip reader. A page is considered visited if it was seen while magnified.

\section{Description of Informal Evaluation Research Participants}

We used the last design session of the Fall 2001 semester as an opportunity to informally evaluate our book readers. We invited our research team to bring their parents, siblings, and friends and ended up having 16 children, aged 5 to 11 (see Table 1 for ages), from diverse backgrounds, including four children of color. Seven of the children were part of our design team, while the remaining were their siblings or friends, and the children of staff. Nine parents also joined. None of the children, including our design partners, had seen any of the readers working before although two of our design partners were involved with the original design. We wanted to independently observe the children using the readers, yet there were not enough adult researchers to do this. We therefore paired each child with one of their parents, having the parents observe their children. If that was not possible, we paired the children with an adult member of our staff.

\begin{tabular}{|c|c|}
\hline $\begin{array}{c}\text { Age } \\
\text { (average 8.6) }\end{array}$ & $\begin{array}{c}\text { Number of } \\
\text { participants }\end{array}$ \\
\hline 5 & 1 \\
\hline 6 & 1 \\
\hline 7 & 2 \\
\hline 8 & 1 \\
\hline 9 & 5 \\
\hline 10 & 2 \\
\hline 11 & 4 \\
\hline
\end{tabular}

Table 1: Ages of participating children

\section{Conditions}

We ran the study with a between subjects design so each child could try all three readers, each with a different book. For the evaluation, we changed the order of the readers, but kept the order of the books the same. The books we used, in the order they were shown, were: Underground Train by Mary Quattlebaum and Cat Bowman Smith (32 pages) [37], The Very Busy Spider by Eric Carle (26 pages) [8], and Elmer by David McKee (31 pages) [32]. Changing the order of the readers yielded six different conditions. Children were assigned evenly to conditions, with four conditions assigned three children each, and two conditions assigned two children each.

\section{Tasks and Data Gathering}

The task assigned to the children was to read the books and answer two content-related questions about each book, such as: "What do the monkeys snack on at the zoo?" (for Underground Train), "Who talks to the spider after the cat?" (for The Very Busy Spider), and "What did Elmer do to look like the other elephants?" (for Elmer). These questions were given to them before reading the books as part of a questionnaire. The children then attempted to answer the questions as they read each book. All the questions were about parts of the books that were midway through the story. After they were done reading a book, the children had to answer two more questions, giving feedback on how they liked the book they just read and the book reader they used. They answered these questions by circling a sad face, a neutral face, or a happy face. After they were done with all three books, the children were asked to select which book they preferred, and which book reader they preferred.

We also gave the adults paired with children a questionnaire. For each book reader used, we asked the adults whether the children were confused or excited about the reader, and whether they thought the reader helped the children answer the questions. After the children were done with all three readers, we asked the adults which reader helped the children the most in understanding the story, and which reader they would prefer the children use.

Besides collecting data from questionnaires, we logged the use of each reader. The logs kept track of the pages that were visited, zoom in's and zoom out's for the comic strip and the spiral reader, and the amount of time spent in each page.

Setup

All research participants performed the study at roughly the same time in two large rooms. Since our participants arrived at different times, they started the evaluation at staggered times. There were enough computers in the two rooms so that there was at least one unused computer between two subjects. Once a child was paired with an adult, an adult researcher led them to a computer, gave them the questionnaires, and explained to them what they were going to do. The adult researchers (not the adults paired with the children) took care of starting and closing each reader. The children were asked to call them when they were done with a book. Questions about how to use the readers were answered if asked by the children or the adults. The adults were told to observe and not tell the children what to do, or operate the computer. A majority of participants completed the evaluation within 30 minutes, and all completed the evaluation within 45 minutes. 


\section{Results of Informal Evaluation}

Given the informal nature of the evaluation and the small number of research participants, we decided not to use exhaustive statistical methods to analyze the data. Instead, we provide a frequency summary of our observations based on the data collected, together with some tables and charts to illustrate the suggestive results.

The questionnaires yielded information on the preferences of both children and the adults that were paired with them (Table 2). Children's preferences were similar when it came to book readers. While more children preferred the standard reader, if we only consider children under 10 , the standard reader was the least popular. Adults, on the other hand, had a clear favorite: the comic strip reader. They also thought the comic strip reader helped children the most in understanding the stories they were reading. When it came to stories, children had a clear favorite: Elmer. However, this did not have an impact on the rating of the readers because the readers were rated evenly across all books (Table 3).

\begin{tabular}{|l|c|c|c|l|}
\hline Reader & $\begin{array}{l}\text { All } \\
\text { children }\end{array}$ & $\begin{array}{l}\text { children } \\
\text { under } \\
\mathbf{1 0}\end{array}$ & adults & $\begin{array}{l}\text { adult's } \\
\text { perception of } \\
\text { help in } \\
\text { understanding }\end{array}$ \\
\hline $\begin{array}{l}\text { comic } \\
\text { strip }\end{array}$ & 4 & 3 & 10 & 8 \\
\hline spiral & 5 & 4 & 2 & 1 \\
\hline standard & 7 & 2 & 4 & 5 \\
\hline
\end{tabular}

Table 2: Preferred readers for all children, children under 10, adults, and reader adults thought helped children the most in understanding the story (two adults did not respond to this last question).

\begin{tabular}{|l|c|c|}
\hline Book & $\begin{array}{l}\text { children's } \\
\text { preference }\end{array}$ & $\begin{array}{l}\text { average rating of } \\
\text { reader }\end{array}$ \\
\hline Underground Train & 4 & 1.4 \\
\hline The Very Busy Spider & 1 & 1.5 \\
\hline Elmer & 11 & 1.4 \\
\hline
\end{tabular}

Table 3: Book preferences and average rating of readers by book. A sad face was assigned a rating of 0 , a neutral face a rating of 1 , and a happy face, a rating of 2 .

Looking at the answers given to the questions at the story level, most children managed to answer all reading comprehension questions. Only three children answered questions incorrectly asked about three different stories using three different readers. There were no major differences in the ratings of the readers (Figure 7).

Adult observers suggested that the spiral and comic strip readers were the most confusing to the children, while at the same time they were the most exciting. This is not surprising, as it is common in visual design for the most

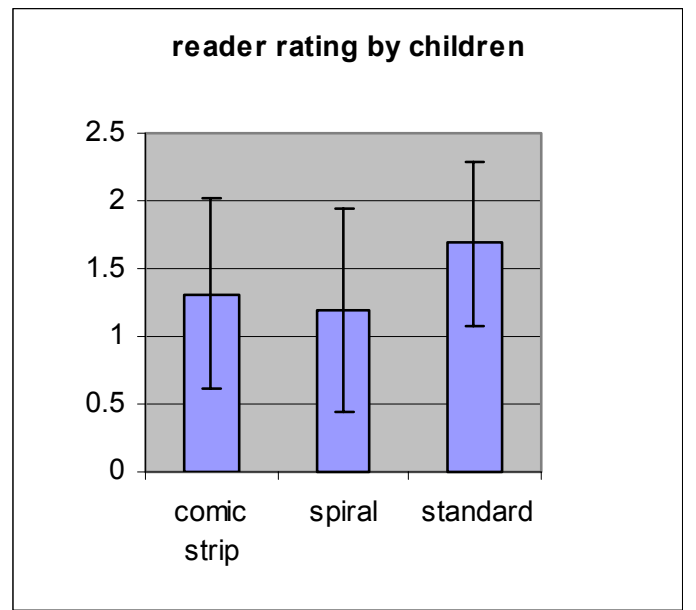

Figure 7: Reader ratings by children. A sad face was assigned a rating of 0 , a neutral face a rating of 1 , and a happy face, a rating of 2. Error bars are two standard deviations in length.

exciting visualizations to be the most confusing. Adult observers also thought the comic strip helped children the most in answering the content questions. Table 4 shows the results.

\begin{tabular}{|l|c|c|c|}
\hline Reader & confusing & exciting & helpful \\
\hline comic strip & 4 & 8 & 11 \\
\hline spiral & 6 & 7 & 4 \\
\hline standard & 0 & 3 & 6 \\
\hline
\end{tabular}

Table 4: Number of adult observers that thought each of the readers was confusing, exciting or helpful

Analyzing the logs did not yield major differences between the readers. As a matter of fact, when looking at time spent in each reader, the number of pages visited, and the number of changes of direction, there are no clear differences between the readers across the three books. Nonetheless, we did find two minor trends:

- On average, children spent more time reading all three books when using the spiral reader.

- The spiral reader had the most time spent, page changes and changes of direction when reading Elmer.

In both cases though, the differences with the other readers were small, within one and a quarter standard deviations. Figure 8 shows the corresponding charts.

There were also no major differences in the number of zoom in's and zoom out's between the comic strip and the spiral reader. However, the fact that children zoomed suggests that at some point they found it useful to get an overview of the books they were reading. Some children also jumped from one part of the book to another, 

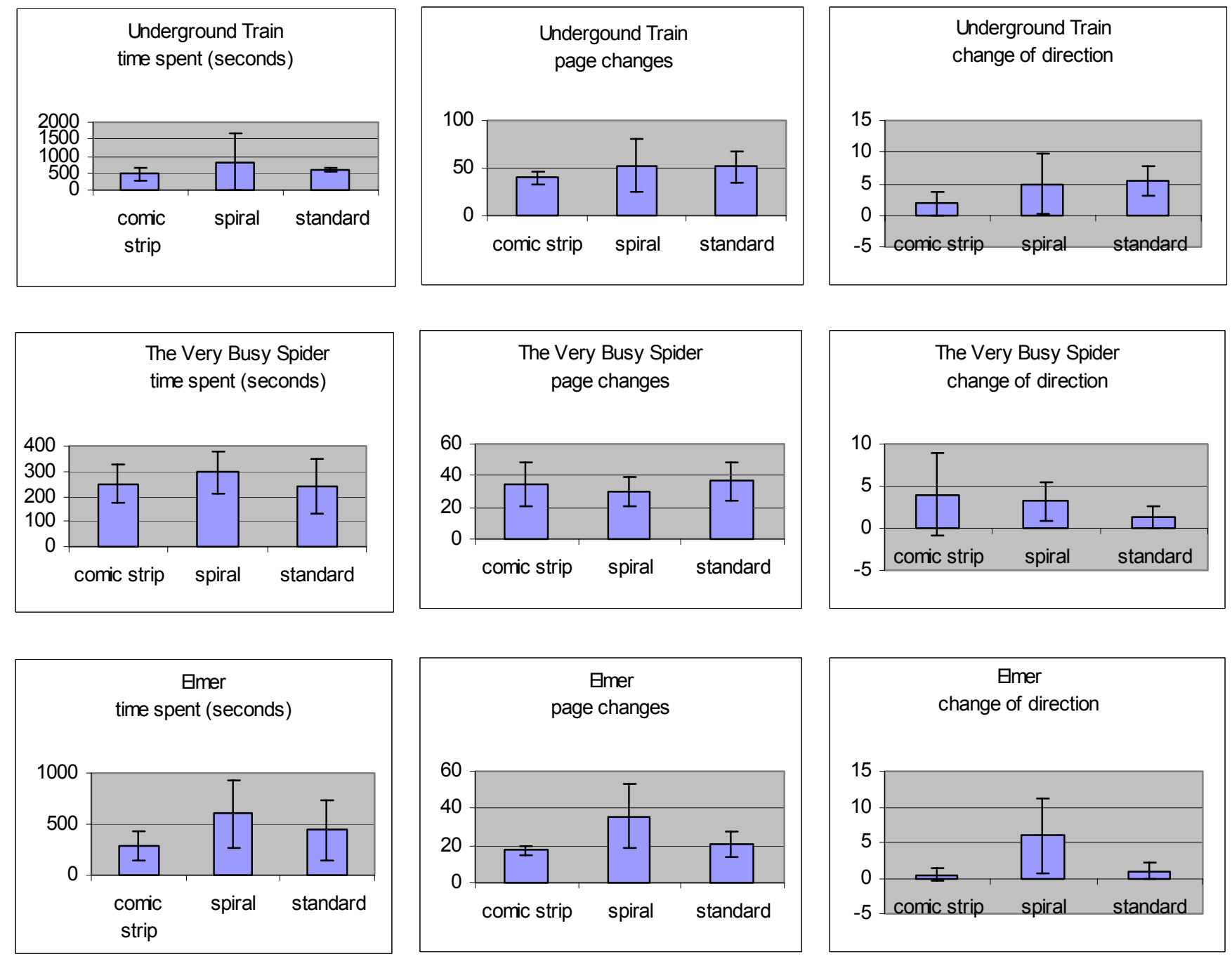

Figure 8: Charts showing log data for time spent (in seconds), number of page changes, and number of changes of direction for each book read under each type of reader. The error bars are two standard deviations in length.

suggesting again that this type of capability may be useful to some children under some tasks.

Overall, the results of the evaluation show that there is no clear winner. Different children prefer different readers. This suggests that pursuing multiple solutions for book readers may be a reasonable path. It also encourages us to find out more about why children prefer their favorite reader, and what tasks are better suited for each type of reader.

\section{FUTURE WORK}

We plan to further examine the possibilities of other book readers. In particular, we would like to investigate a book reader showing small thumbnails of all pages as a way to navigate the book while at the same time showing the current page large enough so it can be read. This would be a child-friendly version of the navigation bar in commercial products. Besides studying other types of readers, we need to further evaluate the readers we developed for this informal evaluation with more children. In particular, we would like to determine what tasks the different readers are better suited for.

We also plan to make the interface components we developed for SearchKids highly configurable so they can be easily used with any digital library, including the ICDL. Developing the interface for the ICDL will also include working on the book club interface and ways of searching using text. We also plan to start building a large collection of books so we can learn how to deal with issues of scale.

\section{CONCLUSION}

This is just the beginning of our work in this area. We currently have a working prototype of a system with searching and browsing capabilities. We have also gained some initial insights into book readers. The main lesson is that different children prefer different types of readers. This means we need to learn more about what tasks are better suited for each reader, and why different children prefer different readers. It also means that current 
commercial book readers are likely not sufficient to satisfy children's diverse needs.

\section{ACKNOWLEDGEMENTS}

This work could not have been accomplished without our child design partners and the lab's staff members and students that helped with our informal evaluation. We would also like to thank Brewster Kahle and Jane White from the Internet Archive for their support and ideas. This project has been funded by the National Science Foundation's DLI-2.

\section{REFERENCES}

1. Adobe Acrobat eBook Reader Home Page. Available at http://www.adobe.com/products/ebookreader/main.html.

2. Ahlberg, C., Williamson, C., \& Shneiderman, B. (1992). Dynamic queries for information exploration: an implementation and evaluation. In Proceedings of Human Factors in Computing Systems (CHI 92), ACM Press, pp. 619-626.

3. Antelope Publishing Home Page. Available at http://www.antelope-ebooks.com.

4. Bederson, B.B., Meyer, J., Good, L. (2000). Jazz: An extensible zoomable user interface graphics toolkit in java. In Proceedings of User Interface and Software Technology (UIST 2000), ACM Press, pp. 171-180.

5. Bettelheim, B. (1976). The uses of enchantment: The meaning and importance of fairy tales. New York: Knopf.

6. Book Adventure Home Page. Available at http://www.bookadventure.com.

7. Campbell, J. (1988). The power of myth. New York: Doubleday.

8. Carle, E. (1984). The Very Busy Spider. New York: Putnam Books for Young Readers.

9. Cass, J. (1967). Literature and the young child. London: Longmans, Green \& Co.

10.CHILDE Project Home Page. Available at http://www.bookchilde.org.

11.DeHirsch, K., Jansky, J.J., \& Langford, W.J. (1966). Predicting reading failure. New York: Harper \& Row.

12.Dillon, A. (1994). Designing Usable Electronic Text: Ergonomics Aspects of Human Information Usage. London: Taylor and Francis.

13.Dillon, A. (1999). TIME - a multi-leveled framework for evaluating and designing digital libraries. International Journal on Digital Libraries, Volume 2, Issue 2/3, pp 170-177.

14. Druin, A. (1999) Cooperative inquiry: Developing new technologies for children with children. In Proceedings of ACM CHI 99 Conference on Human Factors in Computing Systems, ACM Press, pp. 223-230.
15. Druin, A., Bederson, B., Hourcade, J. P., Sherman, L., Revelle, G., Platner, M., \& Weng, S. (2001) Designing a digital library for young children: an intergenerational partnership. In Proceedings of ACM/IEEE Joint Conference on Digital Libraries (JCDL 2001), ACM Press, pp. 398-405

16. Druin, A. (in press) The role of children in the design of new technology. Behaviour and Information Technology (BIT), (in press).

17. Ebook Library at the Electronic Text Center, University of Virginia Home Page. Available at http://etext.lib.virginia.edu/ebooks/.

18.eBooks.com Home Page. Available at http://www.ebooks.com.

19. Editec Communications Home Page. Available at http://www.editec.net.

20.Ellis, G. \& Brewster, J. (1991). The storytelling handbook for primary teachers. England: Penguin Books

21.Erikson, E.H. (1950). Childhood and society. New York: Norton.

22. Fishkin, K., \& Stone, M.C. (1995). Enhanced dynamic queries via movable filters papers. In Proceedings of Human Factors in Computing Systems (CHI 95), ACM Press, pp. 415-420.

23. Furnas, G. W., \& Rauch, S. J. (1998). Considerations for information environments and the navique workspace. In Proceedings of International Conference on Digital Libraries (DL 98), ACM Press, pp. 79-88.

24. Ginsburg, A., Marks, J., Shieber, S. A reader for PostScript documents. In Proceedings of the ACM symposium on User interface software and technology (UIST 96), ACM Press, pp. 31-32.

25.Graham, J. (1999). The Reader's Helper: A Personalized Document Reading Environment. In Proceedings of Human Factors in Computing Systems (CHI 99), ACM Press, pp. 481-488.

26. Grugeon, E. \& Gardner, P. (2000). The art of storytelling for teachers and pupils. London: David Fulton Publishers.

27. Hourcade, J.P., \& Bederson, B.B. (1999). Architecture and implementation of a java package for multiple input devices (MID). Tech Report HCIL-99-08, CS-TR-4018, UMIACS-TR-99-26, Computer Science Department, University of Maryland, College Park, MD.

28. Hourcade, J.P., Druin, A., Sherman, L., Bederson, B.B., Revelle, G., Campbell, D., Ochs, S., Weinstein, B. (in press). SearchKids: a Digital Library Interface for Children. To appear in Extended Abstracts of Human Factors in Computing Systems (CHI 2002). 
29.ipicturebooks Home Page. Available at http://www.ipicturebooks.com.

30.Jones, S. (1998). Graphical query specification and dynamic result previews for a digital library. In Proceedings of User Interface and Software Technology (UIST 98), ACM Press, pp. 143-151.

31. Malkina, N. (1995). Storytelling in early language teaching. Forum, 33, 1, 38.

32. McKee, D. (2001). Elmer. New York: Lothrop, Lee \& Shepard Books.

33. Meek, M. (1982). Learning to read. London: Bodley House.

34. Microsoft Reader Home Page. Available at http://www.microsoft.com/reader/default.asp.

35. Moore, P., \& St. George, A. (1991). Children as information seekers: The cognitive demands of books and library systems. School Library Media Quarterly, 19, pp. 161-168.

36. O’Hara, K., Sellen, A. (1997). A comparison of reading paper and on-line documents. In Proceedings of Human Factors in Computing Systems (CHI 97), ACM Press, pp. 335-342.

37. Quattlebaum, M., Bowman Smith, C. (1997). Underground Train. New York: Doubleday Books for Young Readers.

38. Reading Tree Home Page. Available at http://fusion.sims.berkeley.edu/ReadingTree.
39. Revelle, G., Druin, A., Platner, M., Weng, S., Bederson, B. Hourcade, J. P., \& Sherman, L. (in press). A visual search tool for early elementary science students. Journal of Science Education and Technology.

40. Shneiderman, B. (1998). Designing the User Interface: Strategies for Effective Human-Computer Interaction, Third Edition. Reading, Massachusetts: AddisonWesley.

41. Solomon, P. (1993). Children's information retrieval behavior: a case analysis of an OPAC. Journal of American Society for Information Science, 44, pp. 245264.

42. Theng, Y.L., Mohd-Nasir, N., Buchanan, G., Fields, B., Thimbleby, H., \& Cassidy, N. (2001). Dynamic digital libraries for children. In Proceedings of $A C M / I E E E$ Joint Conference on Digital Libraries (JCDL 2001), ACM Press, pp. 406-415.

43. Time Warner Bookmark/Little, Brown and Company Books for Children Home Page. Available at http://www.twbookmark.com/children.

44. Tundra Books Online. Available at http://www.tundrabooks.com.

45. Walter, V. A., Borgman, C. L., \& Hirsh, S. G. (1996). The science library catalog: A springboard for information literacy. School Library Media Quarterly, 24, pp. 105-112.

46. Wright, A. (1995). Creating stories with children. England: Oxford University Press. 